\title{
Three-Dimensional Structural Modeling of Hu2 Block, HuanJiang Oilfield,
}

\section{Ordos Basin}

\author{
WangWeilin ${ }^{1, \text { a Liu Longlong, }}$ Liu Xiaodong ${ }^{1, ~ c}$ Du Pengwei, d Liu Quyang, ${ }^{1, e}$ \\ ${ }^{1}$ PetroChina Changqing Oilfield Company, Xi'an, China \\ ${ }^{2}$ College of Resources Science \& Technology, Beijing Normal University, Beijing,China \\ aemail:wawl7_cq@petrochina.com.cn; \\ bemail:liulonglong0309@126.com;'email:liuxd_cq@petrochina.com.cn;'demail:dupw7_cq@petrochi \\ na.com.cn;eemail:liuqy_cq@petrochina.com.cn
}

Keywords: Three-dimensional structural modeling, sequence stratigraphy classification, horizon model, Hu2 Block.

Abstract:An underground geologic model which can reflect the structural characteristics as precise as possible is very important for oil and gas exploration and production. Three-dimensional structural modeling technique provide an effective method for subsurface formation architectural description. This article aims at building a three-dimensional structural model of Hu2 Block in order to study the insight features of the interested reservoir. For this purpose, core observation and sequence stratigraphy classification is done first to gain the base information through single well data. Then combinethe dispersive data with the help of interpolation method to set up a three-dimensional structural model.

\section{Introduction}

Three-dimensional (3D) structural modeling is a concept of depicting regional formation features including fault system development, strata interfaces and special structural patterns and other respects ${ }^{[1-4]}$. The 3D structural model has a congenital advantage over the conventional two-dimensional (2D) structural model in terms of a full range of perspectives, details on formation patterns between wells and the design of new wells and so on. Moreover, when it comes to tectonic stress simulation and analysis, a 3D structural body model would nicely meet the demand of a parameter vector for different conditional simulation ${ }^{[5]}$. Because the existing of fault systems influences the formation's completeness and continuity, faults should be fully considered. To build a 3D structural model, the structural information that one-dimensional (1D) well data express are well organized and checked.

There are several interpolation methods for structural modeling such as convergent interpolation, Kriging, cos expansion method and minimum curvature interpolation method. In this case study, the minimum curvature interpolation method is used for structural modeling of the target area.

\section{Geologic settings}

The Ordos Basin is located in the center of the North China Plate and it is an important sedimentary basin rich in oil and gas resources ${ }^{[6]}$. In the north of the basin is Yimeng uplift and Weibei uplift in the south; the west is bounded by Western edge thrust belt and the east is limited by Jinxi folding belt. In tectonic sense, the basin is made up by six secondary order structural 
units.Huanjiang oilfieldis located in the mid-west of Ordos Basin and hydrocarbons were discovered and put into production in the 1970s. The target area, Hu2 Block, is adjacent to Huanxian in the northwest and the city of Qingyang in the southeast. The Chang6 Member in the target area was explored since 2008a and considerable production was gained. Vertically, the Chang6 Member was sub-divided into five layers, namely Chang61, Chang62, Chang63.So far in this area, no fault system has been detected.
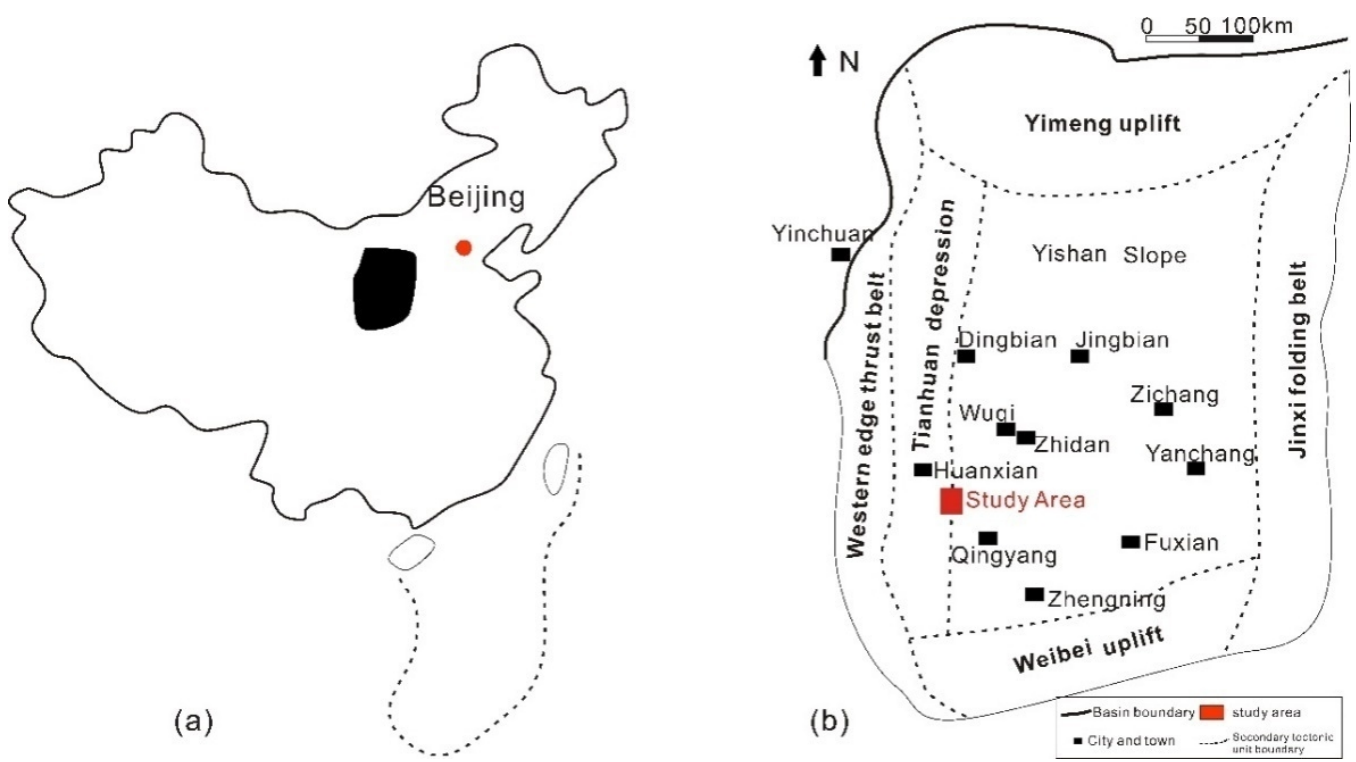

Fig 1 (a) Location of Ordos Basin. (b) The study area in Ordos Basin. (Modified from Xiong, 2016)

\section{Method and workflow}

The workflow applied in the case study start from getting necessary point data which refer to sequence stratigraphic makers and layering data (Fig 2). The sequence stratigraphic makers are combined to produce isochronous modeling lines and the layering data are considered as individual structural points which are used to generate numeric structural lines. Afterwards, both isochronous lines and numeric lines are applied to create structural surfaces namely horizon models. At the end, fulfill the superimposed horizon models with geological bodies and a 3D structural model is established.

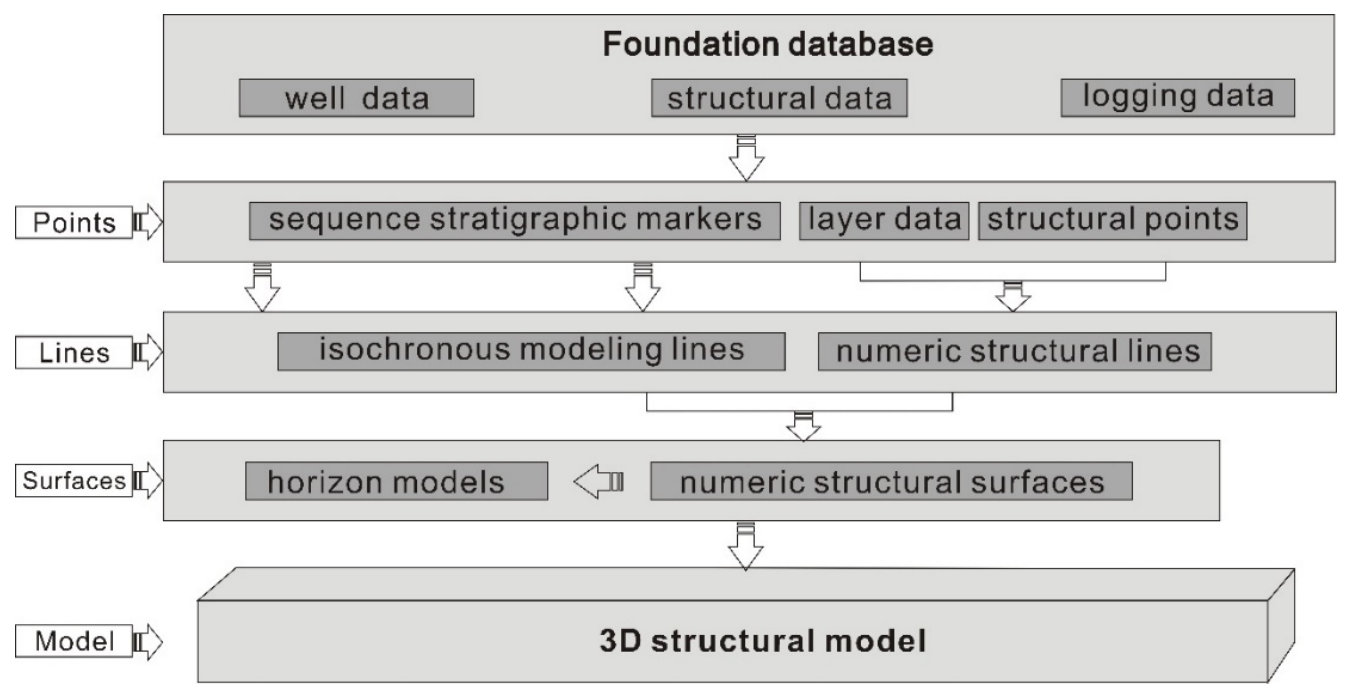

Fig 2 Workflow for 3D structural modeling

\section{Sequence stratigraphy classification}

Based on core observation and electriclog analysis, the three subdivided layers of Chang6 
Member can be recognized and traced throughout the whole block. The Chang61 Member is a set of upper-coarsing sedimentary which has an average thickness of approximate $35 \mathrm{~m}$. The Chang62 Member is a set of upper fining deposit which mud is dominant during this period. The sequence boundary between Chang61 and Chang62 is a set of formation which has high AC values, high GR values and high ILM values. The Chang63 Member is the main reservoir of this block and is about $60 \mathrm{~m}$ thick. During this period, a steady set of sand body was deposited with several sets of mudstone, about $6.5 \mathrm{~m}$ in total. There is a steadily developed set of black gray mudstone which can be traced across the region. Electrical logs of this mudstone interval such as AC and GR are both characterized by a box-look with obvious jaggy phenomenon.

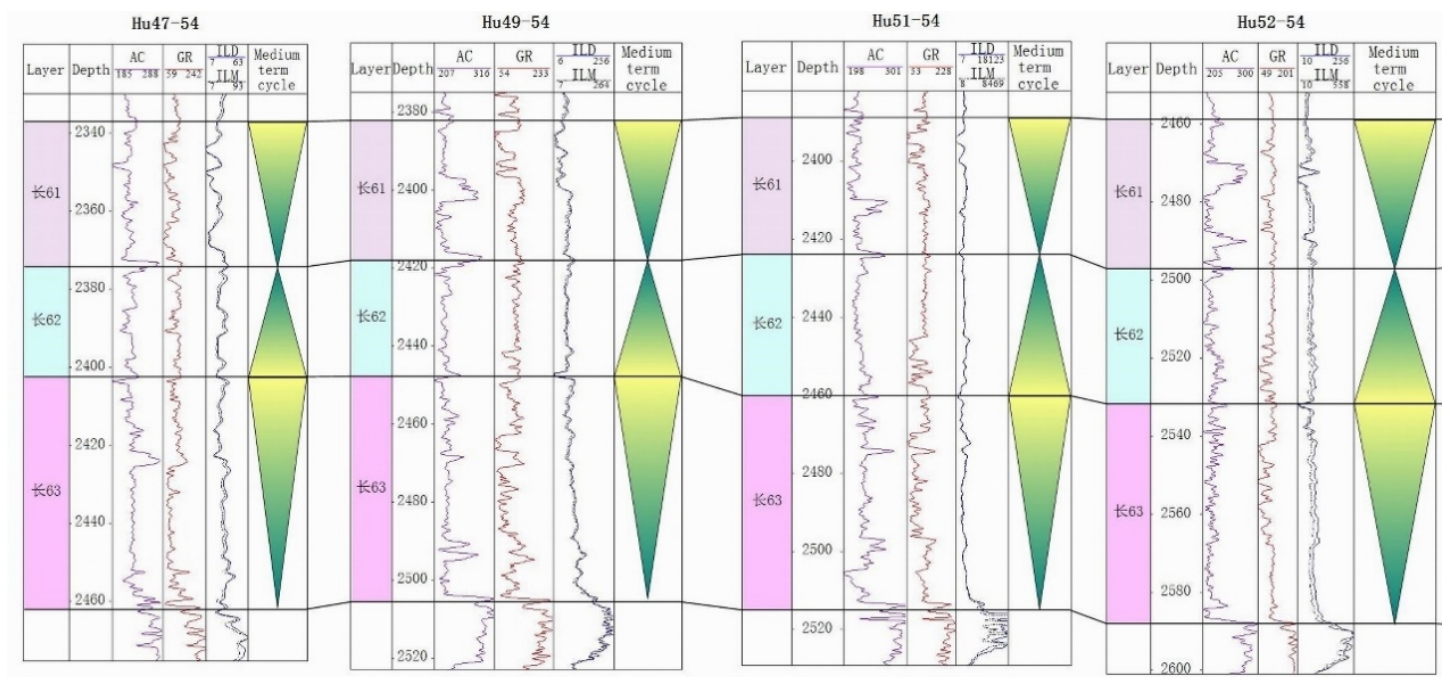

Fig 3 Stratigraphic correlation framework of Hu2 Block. All the three members have relative stable thickness.

\section{D structural modeling}

Usually there are two steps included in the structural modeling-fault modeling and horizon modeling. As mentioned above, no faults have been detected so far, horizon modeling is the key process of 3D structural modeling. The layering data are used as the basic data for horizon modeling and the Minimum Curvature interpolation is used as modeling method for generating horizon models. During horizon modeling, the automatically generated horizon models are usually not consistent with geological understanding. For example, when local formation is undrilled through which means such an area is none-well-controlled and the automatically generated horizon models for this kind of area should be carefully considered and modified according to geologic laws. Through repeatedly adjustment, horizon models of $\mathrm{Hu} 2$ Block were finally built (Fig4). As demonstrated in the figure, the structure in the south is relatively high and down northward. In a whole, the regional structure is flat. The $3 \mathrm{D}$ structural model is finally established when fulfill the space between each horizon models with geological bodies (Fig5, Fig6). 


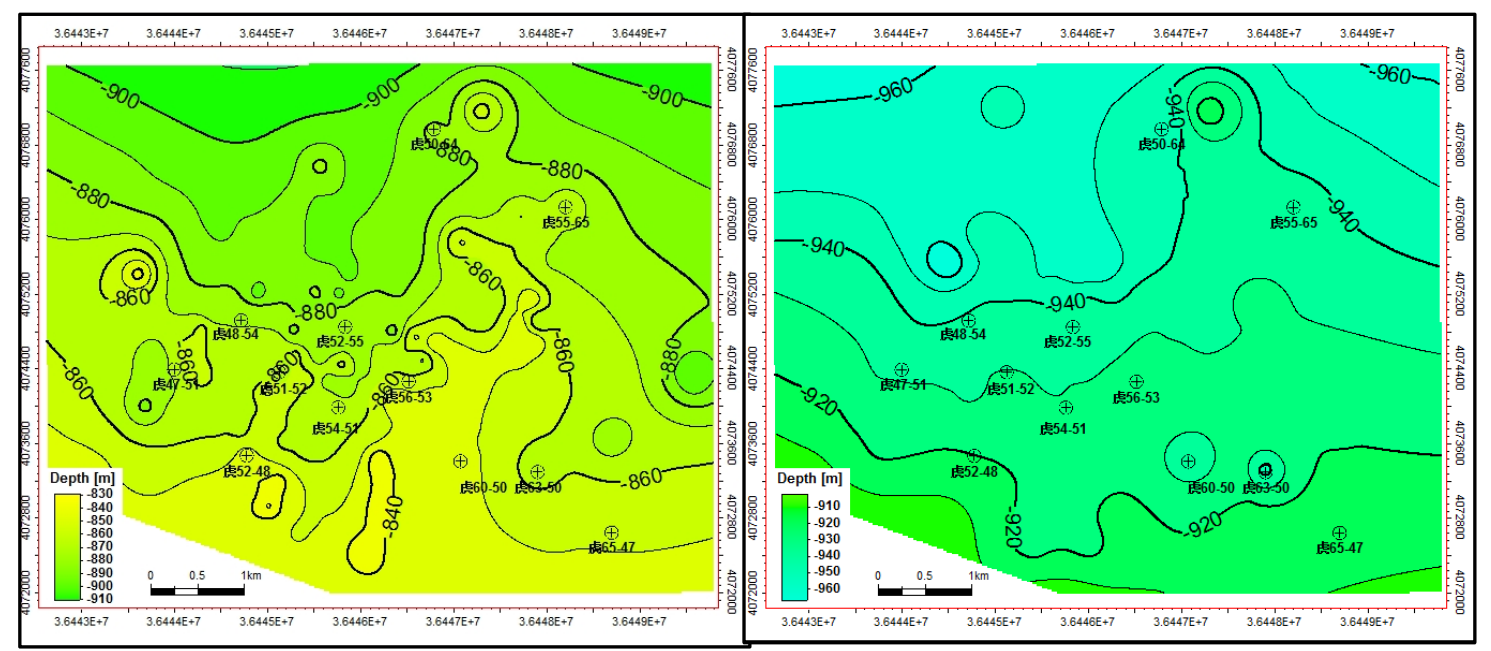

Fig 4 Horizon models for layer Chang62 (left) and layer Chang633 (right). Layer633 is one of subdivided layers of layer Chang63.

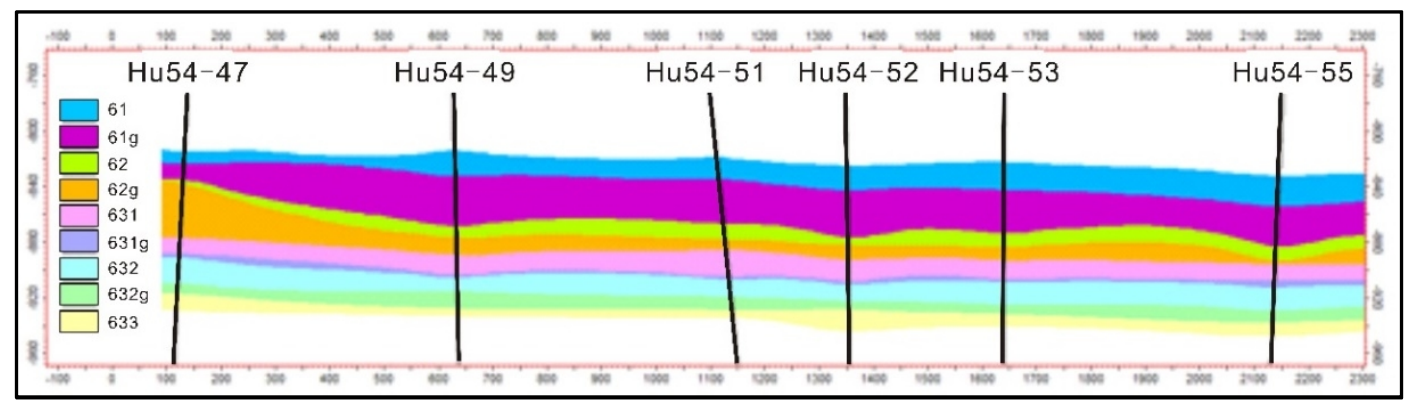

Fig 5 Cross section of the structural model. Showing the formation is relatively stable. While modeling, Chang61 layer is separated into two parts_— the sandstone part, 61 and the mudstone part, $61 \mathrm{~g}$.

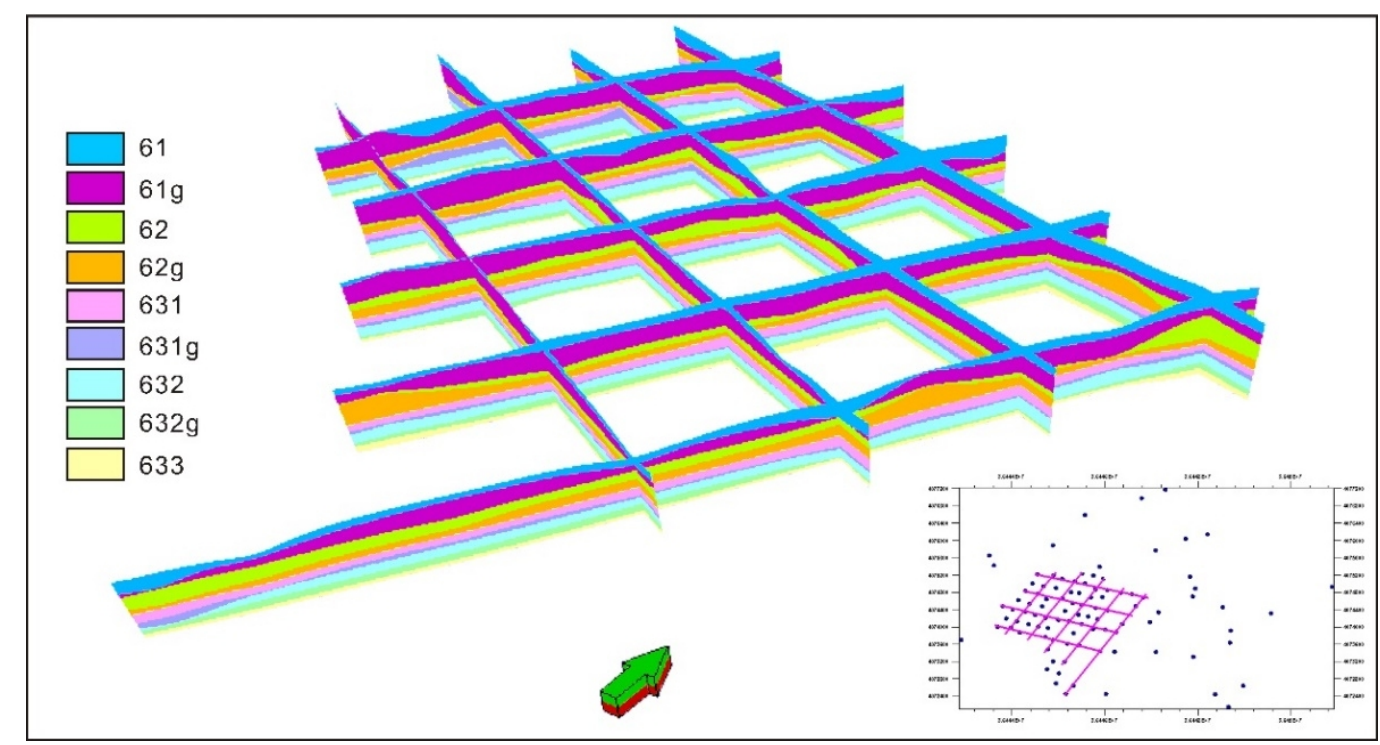

Fig 6 Fence diagram of 3D structural model for Hu2 Block.

\section{Conclusions}

A 3D structural model has been set up based on core observation and sequence stratigraphic classification. The model gives an insight to the internal and external features of the reservoir structure. Formation patterns between certain wells could be well learned with the help of the 3D structure. 3D structural modeling is the key technique of reservoir structure study. 


\section{References}

[1]Sala P, Frehner M, Tisato N and Pfiffner O.A.Building a three-dimensionalnear-surface geologic andpetrophysical model based onborehole data: A case study fromChémery, Paris Basin, France AAPG Bulletin. 97(2013), 1303-1324

[2]Ding F, Zhang JL and Xie J.Fine description of structure and sedimentary microfacies of Li32 block of Lijin oilfield, Dongying depression, China Arabian Journal of Geosciences. 7(2014), 1693-1704

[3]Liu L.L, Zhang J.L, Wang J.K, Li C.L, Yu J.T, Zhang G.X, Fan Z.L, Wei G.Q, Sun Z.Q, Xue H.H, Yu.T and Wang G.Q. Geostatistical modeling for fine reservoir description of Wei2 block of Weicheng oilfield, Dongpudepression, ChinaArab J Geosci. DOI: 10.1007/s12517-015-1924-2 [4]Xu F, Li X,ZhangJ.L, Zhang G.X. Three-dimensional Structural Modeling of Lishui Depression, East Sea Basin. Advanced Materials Research, 853(2014), 663-667.

[5]GuanS.W and HeD.F. Theories and technical frameworks of complex structural modelingActa Petrolei Sinica. 32(2011), 991-1000

[6]Fengyang Xiong, Zhenxue Jiang, Jiafa Chen, Xiangzeng Wang, Zhilong Huang, Guoheng Liu, Feiran Chen, Yirun Li, Lei Chen. The role of the residual bitumen in the gas storage capacity of maturelacustrine shale: A case study of the Triassic Yanchang shale, Ordos, Basin, China. Marine and Petroleum Geology 69(2016), 205-215 